\title{
Dietary Fatty Acid
}

National Cancer Institute

\section{Source}

National Cancer Institute. Dietary Fatty Acid. NCI Thesaurus. Code C68339.

A class of org anic compound that is found in various foods, comprising an alkyl chain with a carboxylic acid end. Naturally occurring dietary fatty acids have a carbon backbone that ranges in length from 4 to 24 units. 